ИЗВЕСТИЯ АКАДЕМИИ НАУК ЭСТОНСКОЙ ССР. ТОМ 21

Химия * ГЕОЛОГИя. 1972. 수 1

УДК $551.243(474.2)$

\author{
В. ПУУРА, А. МАРДЛА
}

\title{
СТРУКТУРНОЕ РАСЧЛЕНЕНИЕ ОСАДОЧНОГО ЧЕХЛА В ЭСТОНИИ
}

За последнее десятилетие в Эстонии достигнуты большие успехи в изучении территории путем глубинного бурения. Более 150 скважин вскрывают полный разрез осадочного чехла, тысячи других - значи тельную часть его. Керны многих скважин детально исследованы стратиграфами и литологами. Это является хорошей предпосылкой для выявления современной структуры и истории формирования осадочных толш. Предлагаемая статья составлена по материалам проводимых начиная с 1965 г. тематических исследований тектоники Эстонии. Кроме авторов, в них принимали участие геологи В. Ряягел, Э. Мардла, А. Вийганд. В. Таалманн, геофизик В. Мосина и другие.

Основной чертой современной геологической структуры территории Эстонии является ее двухчленное строение, характерное для плит древних платформ - на глубоко денудированной выравненной поверхности складчатого кристаллического фундамента архейско-среднепротерозойского возраста залегает тектонически слабо нарушенный и неметаморфизованный платформенный чехол. Последний сложен исключительно из осадочных пород вендского (валдайского), кембрийского, ордовикского, силурийского, девонского и четвертичного возрастов. Мощность чехла сравнительно небольшая даже для платформы - от 100 до $700 \mathrm{M}$. Несмотря на это, разрез чехла, особенно ордовика и силура, весьма полный. Малая мощность чехла обусловлена тем обстоятельством, что территория Эстонии в течение всей платформенной истории оставалась за пределами областей интенсивного осадконакопления,

В современной структуре северо-запада Русской плиты, в пределах территории Эстонии, вендские и палеозойские отложения образуют субширотную моноклиналь, являющуюся переходной зоной между Балтий ским щитом и Балтийской синеклизой.

Слоистость осадочных толщ в общем параллельна поверхности фундамента (см. таблицу).Четвертичные отложения отделены от более древних слоев длительным перерывом и имеют отличные от последних условия залегания. В связи с этим четвертичные отложения можно рассматривать в качестве самостоятельного структурного подразделения осадочного чехла, однако из-за специфичности четвертичного осадконакопления этот вопрос заслуживает отдельного рассмотрения.

Рельеф фундамента весьма плоский. Установленные бурением локальные неровности его обусловлены главным образом тектоническими подвижками платформенной стадии развития. 


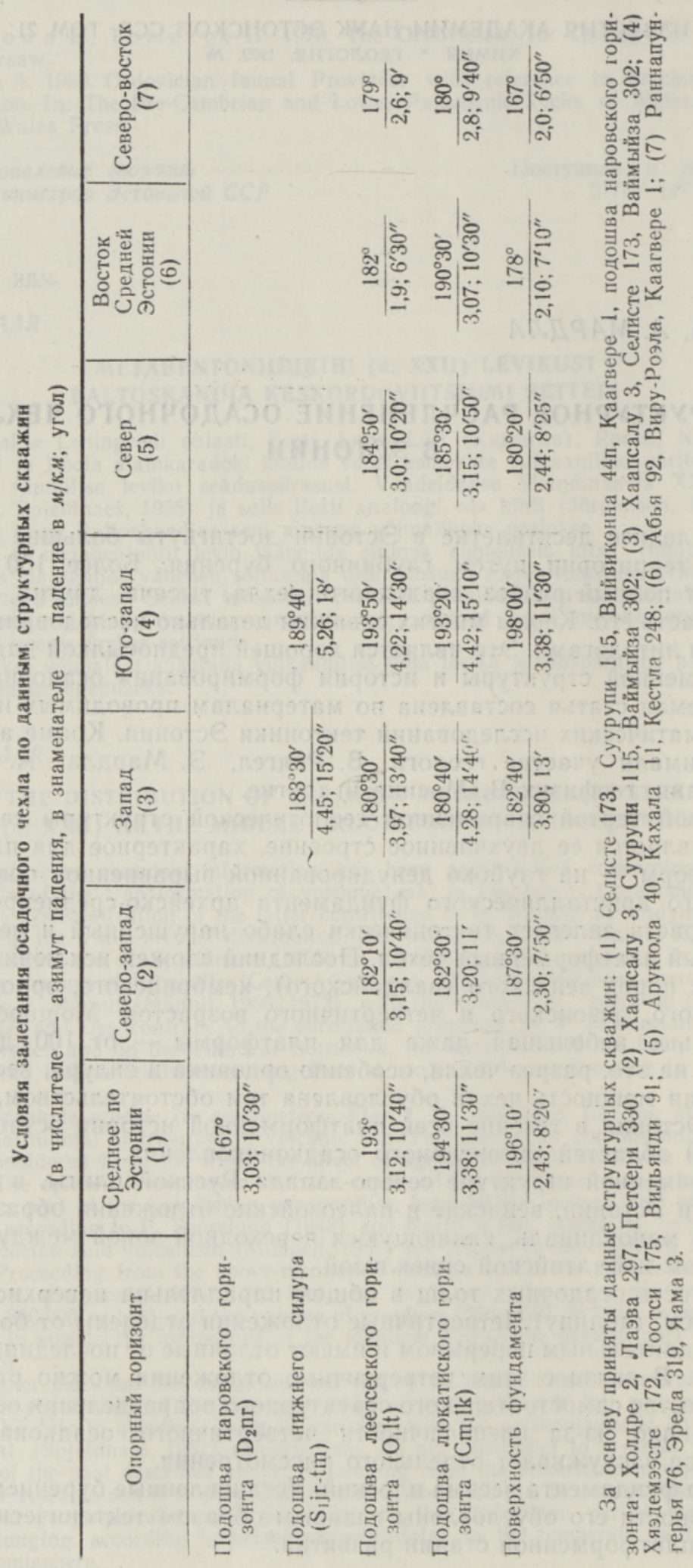



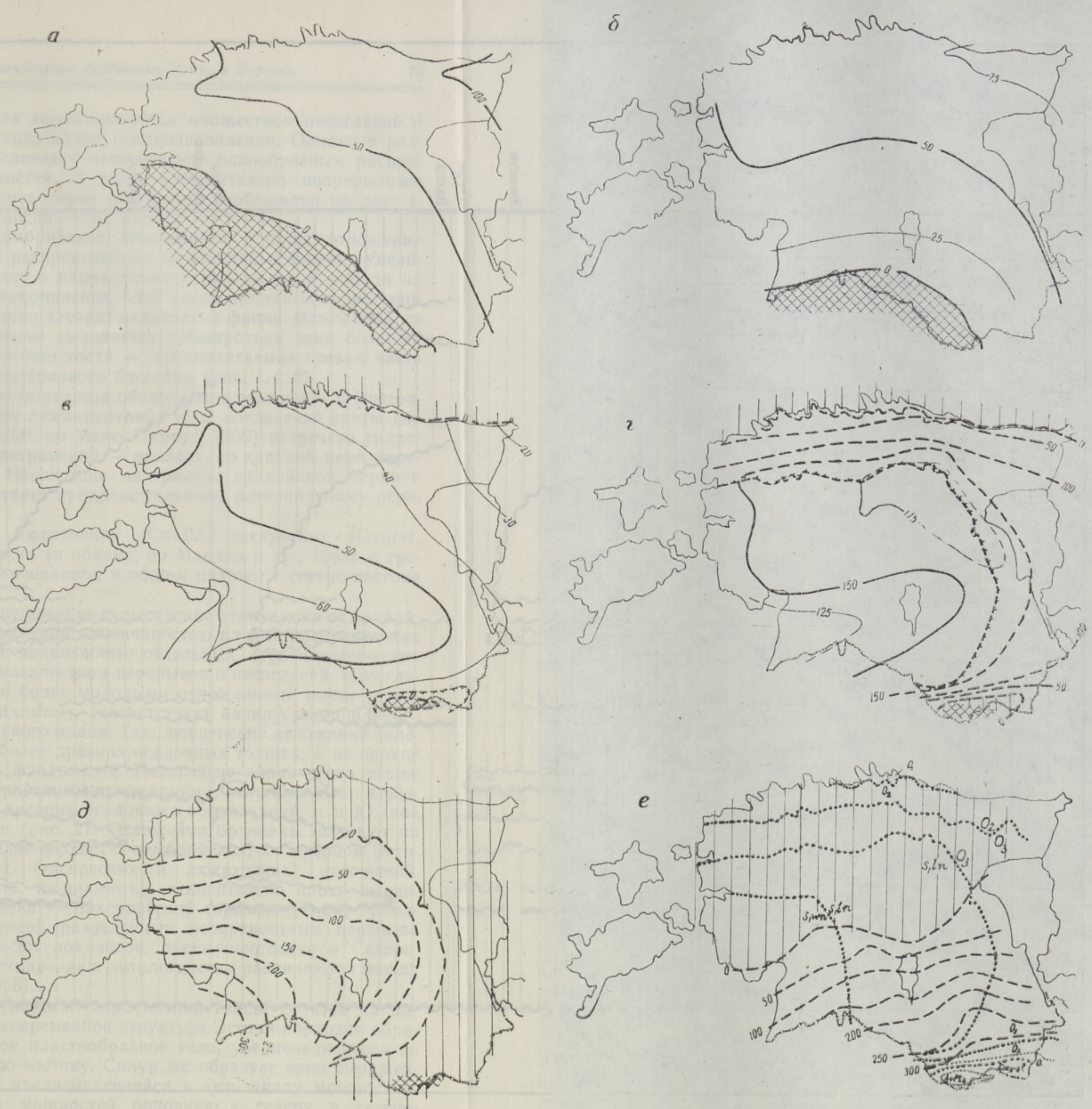

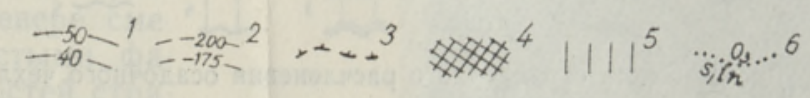

Рис. 1. Распределение мощностей структурных подразделений осадочного чехла.

$a$ - валдайские отложения; 6 - дотрилобитовый нижний кембрий (субхолмиевые слои); в - трнлобитовый ннжний кембрий (холмиевые слон), средний-верх.

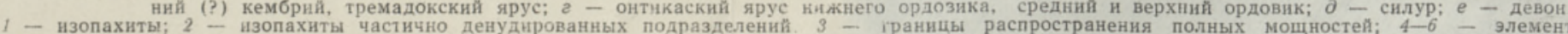
1 - нзопахиты; 2 - изопахиты частично денудированных подразделений. 3 - траницы распространения полных мощностей; $4-6$ - элементы геологии н шалеогеологин; 4 - выход кристаллического фундамента; 5 - ғыход более древних осадочных толщ; 6 - траницы выхода (на поверхности и погребенные) , ндексы возраств. 


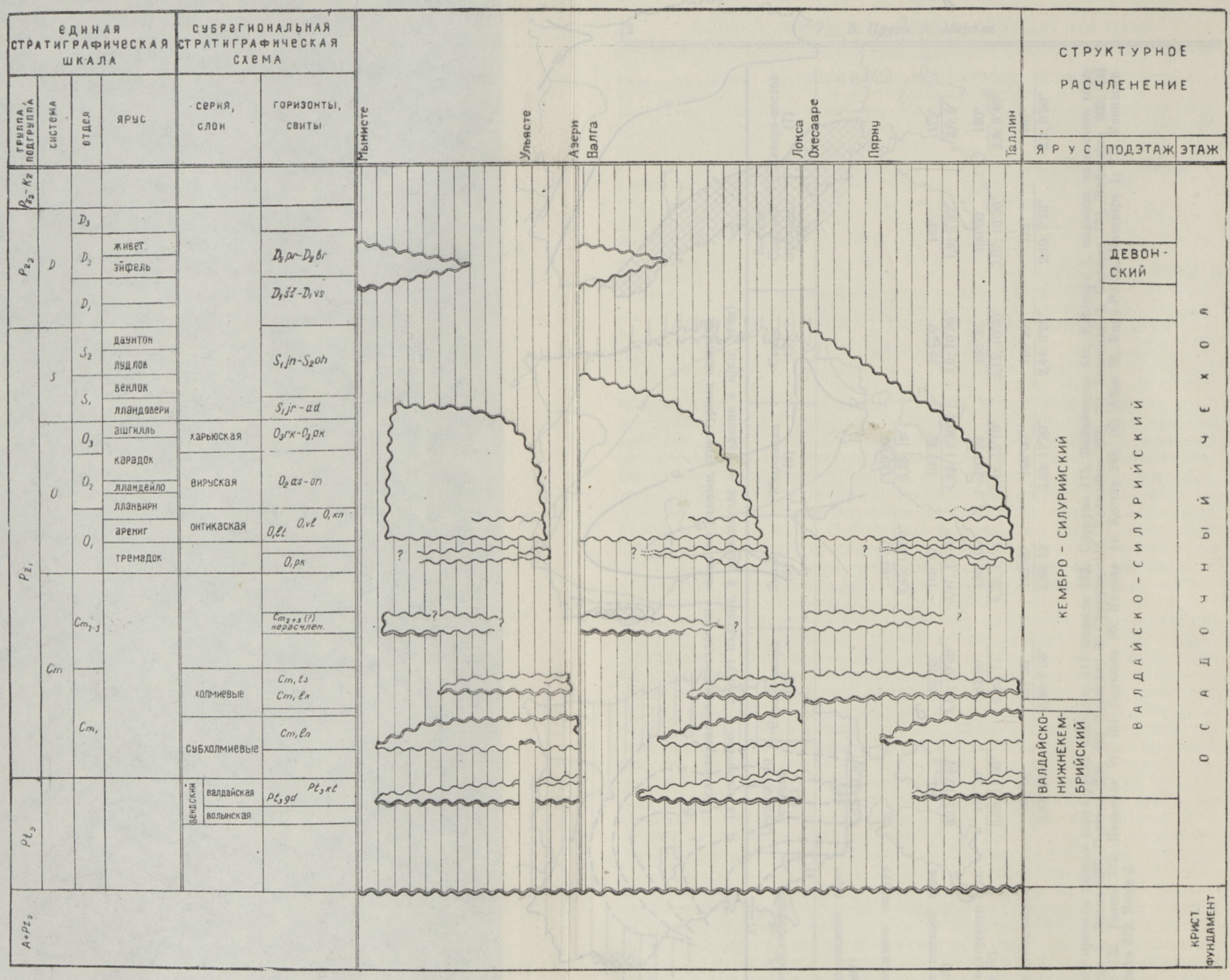

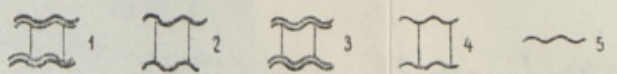

Рис. 2. Схема структурного расчленения осадочного чехла. $1-5-$ характер несогласий:

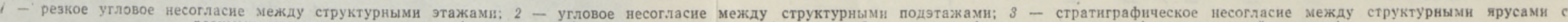

* В понимании Б. Соколова (1965) 
Разрез осадочнӧо чехла характеризуется множеством несогласий и изменчивостью тектонического плана осадконакопления. Однако в раз. резе выделяются подразделения с относительно однообразным распре делением фаций и мощностей, а также относительно непрерывным осадкообразованием. Распределение мощностей изображено на рис. 1 , наличие и характер несогласий - на рис. 2.

Валдайские и нижнекембрийскне лонтоваскне $\left(\mathrm{Cm}_{1} \mathrm{ln}\right)$ отложения характеризуются сходным распределением мощностей и фаций. Увеличение мощностей происходит в направлении с запада и юго-запада на северо-восток, в том же направлении идет смена песчаных и песчаноалевритовых фаций на песчано-алеврито-глинистые фации. Вдоль южного берега Финского залива четко выделяется субширотная зона больших мощностей и наибольшей глинистости - предполагаемая осевая часть открытого на восток заливообразного бассейна (рис. 1, $a, 6)$.

Внутри описываемой части разреза обнаружены перерывы. В Восточ ной Эстонии на поверхности ляминаритовых глин котлинской свиты (на уровне границы $P t_{3} k t^{2}-P t_{3} k t^{3}$, по Менс, Пиррус, 1969) встречена гидро гетитизированная кора выветривания - признак, по крайней мере, перерыва местного значения. Несогласие на границе валдайской серии и нижнего кембрия соответствует продолжптельному региональному пере рыву в осадконакоплении.

Суммарная мощность люкатиских (Cm,lk), тискреских ( $\left.\mathrm{Cm}_{1} \mathrm{ts}\right)$, средне-верхне(?)-кембрийских (в объеме, по Мардла и др., 1968) и тремадокских отложений увеличивается, в общем плавно, с северо-востока на юго-запад (рис. 1,8$)$.

Эти глинисто-песчаные отложения существенно отличаются от валдайско-нижнекембрийских отложений изменчивостью планов распределения мощностей и фашиальной зональности отдельных стратиграфических единиц, а также бо́льшим количеством перерывов и несогласий. Несогла сие между лонтоваскими и более молодыми отложениями имеет регио нальный характер и, по-видимому, соответствует началу регионального переоформления тектонического плана. Так, люкатиские отложения залегагт на разновозрастных более древних осадочных толщах, а на западе даже на кристаллическом фундаменте. Несогласие значительно также под средне-верхне(?)-кембрийскими отложениями, залегающими на раз мытой поверхности более древних осадочных образований, а в Южной Эстонии - на фундаменте (рис. 2). Отложения ордовика залегают на размытой поверхности средне-верхне(?)-кембрийских, в Северной Эстонии - нижнекембрийских (тискреских и люкатиских) отложений. Доордовикская поверхность, по-видимому, относительно плохо выравнена. Нижняя часть ордовика - пакерортский горизонт $\left(\mathrm{O}_{1} \mathrm{pk}\right)$ тремадока - представлена серией разделенных поверхностями перерыва пачек (до 6), которые имеют локальное, пренмущественно в Северо. Западной Эстонии, распространение и литологически различаются между собой (Лоог, Кивимяги, 1968).

Разрез ордовикско-силурийской карбонатной толщи делится на две части: ордовик и силур. В современной структуре Эстонии ордовик образуєт наиболее выдержанное пластообразное тело, увеличивающееся по мощности к северу и северо-востоку. Силур же образует ярко выраженное клинообразное тело с увеличивающейся к юго-западу мощностью.

Увеличение суммарных мощностей ордовика к северу и северовостоку в общих чертах прослеживает смену фациальных зон в обратном направлении - мелководные карбонатные фации на севере сме няются более глубоководными карбонатно-илистыми и илистыми фациями на юге и юго-востоке. В то же время изменение мощностей стра- 
тиграфических подразделений (горизонтов, ярусов, отделов) имеет локальный характер, создавая в целом мозаичное и мозаично-зональное распределение участков больших и малых мощностей (см. Мянниль. 1966, рис. 48-68). В силуре смена мелководных карбонатных фаций на более глубоководные карбонатно-илистые фации происходит в полном соответствии с изменением мощностей с северо-востока на юго-запад в направлении Балтийской синеклизы. На фоне этой общей закономерности выделяются локальные зоны преимущественно запад-юго-западного простирания больших мошностей отдельных стратиграфических единиц (см. Кальо и др., 1970). Для разных стратиграфических единич мсстоположение этих зон различное.

Карбонатная толща ордовика расчленена многими поверхностями перерыва, которые ввиду особенностей литологического состава легко обнаруживаются. В арениге и нижней части лланвирна некоторые из этих поверхностей имеют широкое территориальное распространение и соответствуют перерывам в осадконакоплении в объеме подгоризонта или его части (Орвику, 1960 а, б; Мянниль, 1966). В остальной части раз. реза перерывы также имеют место, однако специально они там не изучались. Ордовик и силур разделены региональной регрессией в конце поркуниского времени (Мянниль, 1966; Кальо и др., 1970).

Девонские отложения имеют совершенно новый по сравнению с силурийскими план распределения мощностей и фациальной зональности отложений. Увеличение мощности и смена континентальных отложенин морскими происходит с севера на юг и юг-юго-восток. Граница распро странения континентальных и морских, в основном терригенных красно шветных отложений, проходила в северо-восточном направлении через Центральную и Юго-Восточную Эстонию. Местоположение этой границы менялось на разных стадиях развития бассейна: нижние свиты и горизонты трансгрессивно залегают на додевонских образованиях и дрvг на друге. Возраст девонских отложений (рис. 2) нами принят по Д. Обру чеву (в печати).

Додевонская поверхность ордовика-силура глубоко денудирована, н, к началу девонского осадконакопления почти вся выравнена. Несмотря на то, что различие азимутов наклона небольшое (см. таблицу), это несо гласие выявлено уже на первых геологических картах (Grewingk, 1878).

Перерывы в осадконакоплении ранее предполагались на границах пярнуского и наровского горизонтов, а также среднего и верхнего девона (Марк, Паасикиви, 1960). В настоящее время существование, по крайней мере, нижнего перерыва считается спорным.

Описанные подразделения осадочного чехла, разделенные несогла сиямн, характеризуют этапы формирования современной геологической структуры территории Эстонии. Определенная этапность проявляется также в возникновении локальных тектонических дислокаций, а также в последующем их оживлении.

В валдайскую эпоху сформировалась древнейшая известная нам локальная тектоническая форма - ульястеская плакантиклиналь, имею шая конседиментационное происхождение, т. е. поднятие блока фундамента происходило во время осадконакопления. $\mathrm{K}$ концу валдайской эпохи формирование ее приостановилось - верхняя регрессивная пачка котлинской свиты частично перекрывает гребень блока (Вахер и др., $1962 ; 1964)$. Оживление в развитии плакантиклинали происходило в тремадоке и после среднего ордовика, вероятно на границе силура и девона

На границе кембрия и ордовика, по имеюшимся данным*, сформи

* Частное сообщение Э. Кала. 
ровался вихтерпалуский сброс (северо-запад Эстонии), претерпевший позднейшее оживление. В ордовике образовалась группа плакантиклиналей на о. Хийумаа (Viiding jt., 1969).

В эпоху регионального поднятия на границе силура и девона территория подвергалась наиболее сильному тектоническому дроблению, о чем свидетельствуют многочисленные нарушения. Наиболее крупным средн них является Рижско-Псковская зона разлома, в своей основной части расположенная на территории Северной Латвии. На северном крыле разлома формировались поднятия фундамента с образованием глыбовых складок в валдайско-силупийской толше (мынистеская, локновская и другие плакантиклинали) (Паасикиви, 1965). На северо-востоке и в цент ральной части Эстонии в пределах широкой Пярну-Нарваской зоны раз ломов появились зоны сбросов (сбросо-флексур) - азериская, ахтме ская (Вахер и др., 1962) и другие. В условиях растяжения по трешинам севедо-восточного простирания образовались «трещины-жилы» (Газизов 1958), заполненные песчаным материалом трешины. Вдоль зон сбросов. безамплитудных зон дробления и отдельных трешин развивался карст. Как уже сказано, в эту тектоническую эпоху оживлялись и более древние нарушения (ульястеское и др.).

В эпоху девонского осадконакопления тектонические дислокационные движения ослабились. В Рижско-Псковской зоне разломов имели место конседиментационное оживление подвижек. а после девона, по-видимому. повторные подвижки. На северо-востоке Эстонии имеются доказатель ства о посленаровском (послесреднедевонском) оживлении зон тектони ческого дробления северо-восточного простирания (Вахер и др., 1962).

Верхняя поверхность девонских, а также более древних отложений в полосах их выходов под четвертичные отложения весьма сильно расчле нена под воздействием преимущественно кайнозойских процессов дену дации.

Основываясь на приведенных данных о несогласиях в геологическом разрезе, об изменениях тектонического плана осадконакопления и о локальных тектонических нарушениях, напрашивается вывод о делении осадочного чехла на три части (рис. 2). Нижняя часть объединяет в себе, безусловно, вендские и нижнекембрийские лонтоваские отложения, средняя - ордовикские и силурийские карбонатные толщи, верхняя - девонские отложения. Затруднение вызывает отнесение отложений, начиная от нижнекембрийских люкатиских и до нижнеордовикских пакерортских, к определенной - нижней или средней - части разреза. Как указано выше, эти относительно небольшие по мошности толши разделены многочисленными перерывами и несогласиями. Принимая во внимание надежно устанавливаемое различие плана распределения мощностей лонтоваской и люкатиской свит (рис. 2), названные толщи отнесены к среднему структурному подразделению разреза.

Выделенные три части разреза осадочного чехла Эстонии имеют, в свою очередь, вполне определенное структурное содержание и каждая из них соответствует определенному геологическому этапу осадконакопления на изучаемой территории. Две нижние части выделяются нами в качестве структурных ярусов, объединяемых в нижний, вендско-силурий ский структурный подэтаж. Это отличается от принятого Н. Иголкиной и др. (1970) структурного расчленения чехла Русской плиты: наши вендско-нижнекембрийский и кембро-силурийский ярусы соответствуют единому, второму снизу, структурному ярусу указанных авторов.

Несогласие между средней и верхней частями разреза более существенно, чем между нижней и средней частями. Оно характеризуется, кроме резкой смены планов осадконакопления, интенсивным тектониче- 
ским дроблением и денудацией территории во время континентального перерыва, а также резкой сменой формационного характера отложений.

Эти обстоятельства позволяют считать границу между силуром и девоном основной, наиболее существенной в геологическом разрезе границей, разделяющей структурные подэтажи платформенного чехла.

Границы выделенных структурных подразделений примерно соответ ствуют рубежам тектономагматических циклов по А. Пронину (1969 а, б) байкальского и каледонского, а также каледонского и герцинского. Дислокационные тектонические движения на территории Эстонии про являлись наиболее интенсивно в позднекаледонскую фазу; о позднебай кальских движениях имеется еше мало данных.

\section{Л ИТЕ РА Т Р А}

В ах ер Р. М., Пу у ра В. А., Эри с ал у Э. К. 1962. Тектоническое строение Северо Восточной Эстонии. Тр. Ин-та геол. АН ЭССР. $\mathbf{X}$.

В ахе р Р. М., Кууспалу Т. И., Пуура В. А., Эрис ал у Э. К. 1964. О геологиче ском положении сульфидных рудопроявлений в районе Ульясте. В сб.: Лито логия палеозойских отложений Эстонин. Таллин.

Г а з и з о в М. С. 1958. К вопросу о морфологии и происхождении глубинного карста в Прибалтийском сланцевом бассейне. Тр. Ин-та геол. АН ЭССР, II.

Иголкина Н. С., Кириков В. П., Крив ская Т. Ю. 1970. Основные этапы фор. мировання осадочного покрова Русской платформы. Сов. геол., № 11.

Каль о Д. Л. (ред.). 1970. Силур Эстонии. Таллин.

Л о о г А., К и в и м я г и Э. 1968. Литостратиграфня пакерортского горизонта в Эстоннн. Изв. АН ЭССР, Хим. Геол., 17, № 4.

Мардла А. К., Менс К. А., КалаЭ.А., Каяк К. Ф., Эрисалу Э. К. 1968 K стратиграфии кембрийских отложений Эстонии. В сб.: Стратиграфиня ниж него палеозоя Прибалтики и корреляция с другими регнонами. Вильнюс,

Марк Э. Ю., Па а си ки в Л Л. В. 1960. Девонская система, Геологня СССР, ХXXIII, Эстонская ССР.

Менс К. А., Пир рус Э. А. 1969. Древняя кора выветривания ляминаритовых глив Северо-Запада Русской платформы. I. Распространение, морфология и зональность строения. Изв. АН ЭССР, Хим. Геол., 18, № 4.

Мл н н иль P. M. 1966. История развития Балтийского бассейна в ордовике. Таллин.

Об ручев Д. В. Знзчение позвоночных для корреляции силурнйских п нижне- и среднедевонских отложений СССР (в печати).

О рв и ку К. К. 1960а. О литостратиграфни волховского и кундаского горизонтов в Эстонин. Тр. Ин-та геол. АН ЭССР, $\mathbf{V}$.

О рвику К. К. 1960б. Литостратиграфические особенности ордовикских горизонтов волхов (В), кунда ( $\mathrm{B}_{\text {III }}$ и азери $\left(\mathrm{C}_{\mathrm{I}} \mathrm{a}\right)$ в северной части Эстонской ССР. Междунар. геол. конгресс, XXI сессия. Докл. сов. геологов. Проблема 7, Стратиграфия и коррелящия ордовика и силура. Л.

П а а си ки в и Л. В. 1966. Геологическое строение и нстория развития Ханья-Локновского и Мынистеского поднятий. Вопр. развед. геофиз., вып. 5.

Прони н А. А. 1969. Каледонский цикл тектонической истории Земли. М.

Пронин А. А. 1969. Герцинский цикл тектонической истории Земли. М.

Соколов Б. С. 1965. Развитие органического мира на рубеже докембрия и кембрия и вендско-кембрийская граница. Всес. совещ. по стратиграфин пограничных отложений докембрия и кембрия (тезисы докладов). Уфа.

Grewing k C. 1878. Geognostische Karte der Ostseeprovinzen. 2. Ausg., Dorpat. Schultz. $\mathrm{V}$ i i d i n g H., K a l a E., P o bu 1 E. 1969. Paluküla môistatus laheneb, Eesti Loodus, nr. 8.

Управление геологии

Совета Министров Эстонской ССР Постушила в ${ }_{27 / \text { редакцию }} 1971$
.

\section{PUURA, A. MARDLA}

\section{EESTI PEALISKORRA STRUKTUURILINE LIIGESTUS}

Pealiskord moodustab ühe struktuurikorruse, milles võib eristada kolm järgmist üks. teisest omaaegsete settebasseinide tektoonilise plaani (joon. 1), kaasaegsete lasumustingimuste (tabel) ning tektooniliste dislokatsioonide intensiivsuse ja iseloomu poolest erinevat 
kihtide kompleksi: 1) valdai seeria ja alamkambriumi lontova lade, 2) kambriumi ülemine osa, ordoviitsium ja silur, 3) devon. Suur diskordantsus esineb teise ja kolmanda kihikompleksi vahel. Kambriumi läbilōike ülaosas ja ordoviitsiumi alumises osas esineb palju katkestus- ning põikseid pindu, kuid vaatamata sellele ei esine alumise kahe kihikompleksi vahel olulisi lasumuse erinevusi. Vastavalt sellele jaotatakse pealiskorra läbilõige kaheks struktuurialamkorruseks: alumine - valdai-siluri alamkorrus, ülemine - devoni alamkorrus. Valdai-siluri struktuurialamkorrus jaotatakse omakorda kaheks struktuurijärguks (joon. 2)

\section{PUURA, A. MARDLA}

\section{THE STRUCTURAL DISSECTION OF THE SEDIMENTARY COVER OF ESTONIA}

The sedimentary cover on the territory of Estonia makes one structural stage, which may be subdivided into three strata complexes, different in the tectonical appearance of the former sedimentary basins (Fig. 1), in recent mode of occurrence and in intensity of tectonical dislocations: 1) Valdai Series and Lontova Stage of Lower Cambrian; 2) the upper part of Cambrian, Ordovician and Silurian; 3) Devonian. There is a remarkable disconformity between the second and third strata complexes, but there is no substantial difference in the occurrence of the first and the second complexes in spite of the numerous rupture and disconformity surfaces in the upper part of the Cambrian and lower part of the Ordovician. Correspondingly, the sedimentary cover is divided into two structural substages: the lower - Valdai-Silurian and the upper - Devonian. The Valdai-Silurian structural substage, in its turn, is divided into two smaller structural units (Fig. 2). 